\title{
CT Screening for Lung Cancer: Importance of Emphysema for Never Smokers and Smokers
}

\author{
${ }^{1}$ Claudia I. Henschke PhD, MD, ${ }^{1,2}$ Rowena Yip MPH, \\ ${ }^{2}$ Paolo Boffetta MD MPH, ${ }^{3}$ Steven Markowitz MD,${ }^{3}$ Albert Miller MD, \\ ${ }^{4}$ Takaomi Hanaoka MD, ${ }^{5}$ Ning Wu MD, ${ }^{6}$ Javier J. Zulueta MD, ${ }^{1}$ David F. Yankelevitz MD \\ for the I-ELCAP Investigators \\ ${ }^{1}$ Department of Radiology, ${ }^{2}$ Institute of Translational Epidemiology, \\ Mount Sinai School of Medicine, New York NY \\ ${ }^{3}$ City University of New York at Queens College, Queens NY \\ ${ }^{4}$ Azumi General Hospital, Nagano, Japan \\ ${ }^{5}$ Cancer Hospital, Chinese Academy of Medical Science, Beijing, China \\ ${ }^{6}$ Clinica Universitaria de Navarra, Pamplona, Spain
}

Corresponding author:

Claudia I. Henschke, Ph.D, M.D

Department of Radiology

Mount Sinai School of Medicine

1 Gustave Levy Place

New York, New York 10029

Tel: $212-241-2821$

Fax: 212-241-9655

Email: Claudia.Henschke@mountsinai.org

Manuscript type: Original Research

Word count: paper: 2,339, abstract 212

Partially funded by a grant from the Flight Attendants Medical Research Institute, the sponsor had no involvement in any study design, data collection, data analysis and interpretation and manuscript writing. 
The I-ELCAP Investigators:

Mount Sinai School of Medicine, New York, NY: Claudia I. Henschke, Principal Investigator, David F. Yankelevitz, Raja Flores, Rowena Yip, Dongming Xu; Weill Cornell Medical College: Dorothy I. McCauley, Mildred Chen, Daniel M. Libby, Olli S. Miettinen, James P. Smith, Mark Pasmantier; Cornell University: A. P. Reeves; CBNS, City University of New York at Queens College, Queens, NY; Steven Markowitz, Albert Miller; Fundacion Instituto Valenciano de Oncologia, Valencia, Spain: Jose Cervera Deval; University of Toronto, Princess Margaret Hospital, Toronto, Canada: Heidi Roberts, Demetris Patsios; Azumi General Hospital, Nagano, Japan: Shusuke Sone, Takaomi Hanaoka; Clinica Universitaria de Navarra, Pamplona, Spain: Javier J. Zulueta, Juan P. deTorres, Maria D. Lozano; Swedish Medical Center, Seattle, WA: Ralph Aye; Christiana Care, Helen F. Graham Cancer Center, Newark, DE: Thomas Bauer; National Cancer Institute Regina Elena, Rome, Italy: Stefano Canitano, Salvatore Giunta; St.Agnes Cancer Center, Baltimore, MD: Enser Cole; LungenZentrum Hirslanden, Zurich, Switzerland: Karl Klingler; Columbia University Medical Center, New York, NY: John H.M. Austin, Gregory D. N. Pearson; Hadassah Medical Organization, Jerusalem, Israel: Dorith Shaham; Holy Cross Hospital Cancer Institute, Silver Spring, MD: Cheryl Aylesworth; Nebraska Methodist Hospital, Omaha NE: Patrick Meyers; South Nassau Communities Hospital, Long Island, NY: Shahriyour Andaz; Eisenhower Lucy Curci Cancer Center, Rancho Mirage, CA; Davood Vafai; New York University Medical Center, New York, NY: David Naidich, Georgeann McGuinness; Dorothy E. Schneider Cancer Center, Mills-Peninsula Health Services, San Mateo, CA: Barry Sheppard; State University of New York at Stony Brook, Stony Brook, NY: Matthew Rifkin; ProHealth Care Regional Cancer Center, Waukesha \& Oconomowoc Memorial Hospitals, Oconomowoc, WI: M. Kristin Thorsen, Richard Hansen; Maimonides Medical Center, Brooklyn, NY: Samuel Kopel; Wellstar Health System, Marietta GA: William Mayfield; St. Joseph Health Center, St. Charles, MO: Dan Luedke; Roswell Park Cancer Institute, Buffalo, NY: Donald Klippenstein, Alan Litwin, Peter A. Loud; Upstate Medical Center, Syracuse, NY: Leslie J. Kohman, Ernest M. Scalzetti; Jackson Memorial Hospital, University of Miami, Miami, FL; Richard Thurer; State University of New York, North Shore-Long Island Jewish Health System, New Hyde Park, NY: Arfa Khan, Rakesh Shah; The $5^{\text {th }}$ Affiliated Hospital of Sun Yat-Sen University, Zhuhai, China: Xueguo Liu; Mercy Medical Center, Rockville Center, NY: Gary Herzog; Shin Kong Wu Ho-Su memorial Hospital, Taipei, Taiwan: Diane Yeh; Cancer Hospital, Chinese Academy of Medical Science, Beijing, China: Ning Wu; Staten Island University Hospital, Staten Island NY: Joseph Lowry, Mary Salvatore; Central Main Medical Center: Carmine Frumiento; Mount Sinai School of Medicine, New York, NY: David S. Mendelson; Georgia Institute for Lung Cancer Research, Atlanta, GA: Michael V. Smith; The Valley Hospital Cancer Center, Paramus NJ: Robert Korst; Health Group Physimed/McGill University, Montreal, CA: Jana Taylor; Memorial Sloan-Kettering Cancer Center, New York, NY: Robert T. Heelan, Michelle S. Ginsberg; John Muir Cancer Institute, Concord CA: Michaela Straznicka; Atlantic Health Morristown Memorial Hospital, Morristown NJ: Mark Widmann; Alta Bates Summit Medical Center, Berkeley CA: Gary Cecchi; New York Medical College, Valhalla, NY: Terence A.S. Matalon; St. Joseph's Hospital, Atlanta GA: Paul Scheinberg; Mount Sinai Comprehensive Cancer Center, Miami Beach, FL: Shari-Lynn Odzer; Aurora St. Luke's Medical Center, Milwaukee WI: David Olsen; City of Hope National Medical Center, Duarte, CA: Fred Grannis, Arnold Rotter; Evanston Northwestern Healthcare Medical Group, Evanston, IL: Daniel Ray; Greenwich Hospital, Greenwich, CT: David Mullen; Our Lady of Mercy Medical Center, Bronx, NY: Peter H. Wiernik; Baylor University Medical Center, Dallas TX: Edson H. Cheung; Sequoia Hospital, Redwood City CA: Melissa Lim; Glens Falls Hospital, Glens Falls NY: Louis DeCunzo; Atlantic Medical Imaging, Atlantic City NJ: Robert Glassberg; Karmanos Cancer Institute, Detroit, MI: Harvey Pass, Carmen Endress; Rush University, Chicago IL: Mark Yoder, Palmi Shah; Building Trades, Oak Ridge TN: Laura Welch; Sharp Memorial Hospital, San Diego, CA: Michael Kalafer; Newark Beth Israel Medical Center, Newark NJ Jeremy Green; Guthrie Cancer Center, Sayre PA: Comprehensive Cancer Centers of the Desert, Palm Springs CA: Elmer Camacho; Dickstein Cancer Treatment Center, White Plains Hospital, White Plains NY: Cynthia Chin; Presbyterian Healthcare, Charlotte NC: James O’Brien; SUNY Downstate, Brooklyn NY: David Gorden; Bend Memorial Hospital, Bend OR: Albert Koch; University of Toledo, Toledo OH: James Wiley 


\begin{abstract}
Purpose: To address the prevalence of lung cancer in high and low-risk people according to their smoking history, age, and CT findings of emphysema.

Methods: We reviewed the baseline low-dose CT scans of 62,124 current, former and never smokers, aged 40-90 to determine the prevalence of lung cancer. We performed logistic regression analysis of the prevalence of lung cancer to determine the odds ratio (OR) for emphysema, conditionally on age, female gender, and ethnicity.

Results: The prevalence of lung cancer was $1.4 \%$ (95\% CI: $1.3-1.6)$ for current smokers, $1.1 \%$ (95\% CI: $1.0-1.2)$ for former smokers, and 0.4\% (95\% CI: $0.3-0.6)$ for never smokers. Emphysema was identified in 29\% (6,684), 21\% (5,422), and 1.6\% (194) of current, former, and never smokers, respectively. The prevalence of lung cancer among current smokers was $1.1 \%$ for those without emphysema vs. $2.3 \%$ for those with emphysema (odds ratio [OR] 1.8; 95\% confidence interval $[\mathrm{CI}]: 1.4-2.2$ ) and the corresponding difference for former smokers was $0.9 \%$ vs. $1.8 \%$ (OR: $1.7 ; 95 \%$ CI: $1.3-2.2$ ), and for never smokers, it was $0.4 \%$ vs. $2.6 \%$ (OR: 6.3; 95\% CI: $2.4-16.9)$.

Conclusions: Identification of emphysema in low-dose CT scans increases the risk of lung cancer and is important in determining follow-up of current, former, and never smokers.
\end{abstract}

Keywords: emphysema, lung cancer, smokers, never smokers, CT screening, 


\section{Introduction}

The number of people who have a CT scan of the chest continues to increase in the United States and throughout the world for many indications, including CT screening for lung cancer. In 2009, it was estimated that in the US alone, almost 10 million CT scans of the chest were performed for lung and cardiac indications (1). It is estimated that over $50 \%$ of these people had at least one noncalcified nodule $(\mathrm{NCN})$ identified in the lung parenchyma, raising the possible diagnosis of lung cancer (2). Beyond the identification of NCNs on CT scans, emphysema has been identified as an important risk factor for lung cancer which appears to be independent of the presence of airflow obstruction as measured by pulmonary function tests (3$6)$.

In light of the high lung cancer fatality rate, the management of findings on CT is of great concern. Different management strategies have been developed with a goal of diagnosing a possible cancer as early as possible while minimizing unnecessary diagnostic tests, invasive procedures, and surgery. These strategies have focused mainly on high-risk smokers in the context of CT screening studies (7-11). The Fleischner Society Guidelines also addressed the recommended workup for NCNs in low-risk individuals, including never smokers (12). These management strategies, however, do not use the information on findings provided by the CT scan other than the presence of NCNs.

In this report we address the prevalence of lung cancer according to the presence of emphysema as identified in the CT scan in both high and low-risk people as defined by their smoking history and age. 


\section{Methods}

Participants $(n=62,124)$ enrolled in a program of CT screening for lung cancer in the International Early Lung Cancer Action Program (I-ELCAP) in 2000 - 2013 (13). At the time of enrollment, all were 40 to 90 years of age (median age of 60) and asymptomatic for lung cancer. Consent for the research was obtained from all participants according to HIPAA-compliant protocols that were approved by the IRBs of the participating institutions.

Smoking status: All participants completed a baseline questionnaire that provided information on their smoking status, quantity smoked, and, if they had quit, when. Smokers were defined as participants who had smoked 100 or more cigarettes and were classified as being a current smoker if they had smoked more than 1 cigarette in the month prior to enrollment or quit within 1 year of enrollment $(n=23,415)$. The remaining smokers were classified as former smokers $(n$ $=26,341)$. Never smokers $(n=12,368)$ were defined as having smoked less than 100 cigarettes in their lifetime; some $32 \%(3,982)$ may have had occupational exposure to lung carcinogens while the rest had some level of secondhand tobacco smoke exposure (SHTS). Current and former smokers were divided into 3 categories according to the total pack-years of smoking: light, if less than 30 pack-years, moderate if 30-59 pack-years, and heavy if 60 or more packyears.

Baseline CT scan and diagnosis of lung cancer: Upon enrollment, the baseline low-dose CT scan was obtained according to a common protocol from the lung apices to the bases in a single breath hold at maximum inspiration at $120 \mathrm{kVp}$ and $80 \mathrm{mAs}$ or less (13). No intravenous contrast material was used. The CT images were read by radiologists at the participating institutions who had undergone training at the center. The readings were performed using standard lung settings (width $1500 \mathrm{HU}$ and level $-650 \mathrm{HU}$ ) and standard mediastinal settings 
(width, $350 \mathrm{HU}$; level, $50 \mathrm{HU}$ ). Diagnoses of lung cancer resulting from the baseline CT scan were documented in the web-based management system and had pathologic confirmation.

Emphysema: The absence/presence of emphysema was ascertained from the baseline low-dose CT image and documented $(6,13)$. Emphysema was considered to be present if discrete areas of decreased attenuation could be identified anywhere in the lung parenchyma, or, if no discrete areas of decreased attenuation could be identified on the CT scan, when the blood vessels were splayed suggesting parenchymal expansion.

Secondhand tobacco smoke exposure score: All participants completed a background questionnaire about secondhand tobacco smoke (SHTS) exposure before age 18 as a child, and after age 18, as an adult at home and at work as previously described in detail (14). The responses determined the permission status, duration of SHTS exposure (years), daily intensity of the SHTS exposure (packs per day) for each of these life-exposures as a child, and as an adult at home and at work. The permission status was 1.0 if smoking was allowed anywhere, 0.5 if smoking was restricted, or 0 if smoking was not permitted. The exposure duration was the sum of the years that the participant was exposed to SHTS divided by the maximum possible score. The total SHTS exposure score ranged from 0 to 0.70 and the entire range was divided into quartiles. The analysis focused on the two highest SHTS quartiles.

Statistical analysis: The prevalence of diagnosed lung cancers and emphysema was determined overall and for each decade of age. Percentages, median and interquartile range (IQR) were calculated as needed. The Chi-square test was used to compare percentages. The prevalence of lung cancer was addressed as a joint function of potential risk indicators using multivariate logistic regression analysis, adjusting for emphysema, age, sex and Asian ethnicity. All analyses were performed using the SAS (SAS, Cary, NC, Version 9.2) statistical package. 


\section{Results}

The characteristics of the 62,124 participants at the time of the baseline CT scan are given in Table 1, separately for current, former and never smokers. On average, former smokers were older than current and never smokers (62 vs. 57 vs. 56 years of age, $\mathrm{P}<0.0001$ ). The median pack-years of smoking was 35 pack-years (IQR: 23-49) for current smokers and 30 (IQR: 19-47) for former smokers. For former smokers, the median years of quitting prior to enrollment was 15 years (IQR: 6-24). Gender and ethnicity were also significantly different between groups.

The prevalence of participants diagnosed with lung cancer as a result of findings on the baseline CT scan was 1.4\% ( $\mathrm{N}=333)(95 \%$ CI: 1.3 - 1.6) for current smokers, $1.1 \%(\mathrm{~N}=283)$ (95\% CI: 1.0 - 1.2) for former smokers, and $0.4 \%(\mathrm{~N}=52)(95 \% \mathrm{CI}: 0.3-0.6)$ for never smokers. Between the age of 40 and 50, the prevalence of lung cancer was the same $(0.2 \%)$ for smokers and never smokers, though the numbers of participants diagnosed with lung cancer were small. After age 50, the prevalence was always higher among smokers than never smokers (Table 2).

For smokers, the prevalence of participants diagnosed with lung cancer increased with increasing cumulative smoking (Table 3). For current smokers, the prevalence was $0.6 \%, 1.6 \%$, and $2.8 \%$ for $1-29,30-59$, and $60+$ pack-years, respectively and for former smokers, the prevalence was $0.4 \%, 1.3 \%$, and $2.4 \%$, respectively. Current smokers with less than 30 packyears had a prevalence of $0.6 \%$, similar to that for former smokers $(0.4 \%)$ and never smokers $(0.4 \%)$, and this remained the same even when adjusted for age.

Emphysema of any extent was identified in $28.5 \%(6,684), 20.6 \%(5,422)$, and $1.6 \%$ (194) of current, former, and never smokers. Like lung cancer, the prevalence of emphysema increased with increasing age (Table 2) and among smokers, it increased with increasing packyears of smoking (Table 3). Unlike lung cancer, however, the prevalence of emphysema for 
current and former smokers was much higher than among never smokers at all ages and all levels of smoking (Tables 2 and 3). Even for light smokers ( $<30$ pack-years), the prevalence of emphysema was $17.5 \%$ and $10.9 \%$ for current and former smokers, 10- and 6-fold higher, respectively when compared with $1.6 \%$ for never smokers (Table 3 ).

For smokers and never smokers with emphysema, the prevalence of lung cancer was $2.1 \%(255 / 12,106)$ and $2.6 \%(5 / 194)$, not significantly different $(\mathrm{P}=0.61)$. The prevalence of lung cancer among current smokers increased from $1.1 \%$ for those without emphysema to $2.3 \%$ for those with emphysema, among former smokers, the prevalence increased from $0.9 \%$ to $1.8 \%$, and for never smokers it increased from $0.4 \%$ to $2.6 \%$. Thus, there was a slightly more than 2 fold increase for current and former smokers while there was a 6-fold increase among never smokers. This increase in the prevalence of lung cancer when emphysema was present was confirmed by the multivariate regression analysis (Table 4). The adjusted odds ratios for the presence of emphysema were 1.8 (95\% CI: $1.4-2.2, \mathrm{P}<0.0001)$ for current smokers, 1.7 (95\% CI: 1.3 - 2.2, P < 0.0001) for former smokers, 6.3 (95\% CI: 2.4-16.9, P =0.0003) for never smokers. To have the same comparison for current, former, and never smokers, pack-years of cigarette smoking was not included in the logistic regression. However when comparing current and former smokers when including pack-years of smoking, the odds ratio for the presence of emphysema remained the same.

In a subset of the cohort whose participants had never smoked cigarettes, detailed information about secondhand tobacco smoke (SHTS) exposure was available on 3,266. Multivariate logistic regression analysis revealed an odds ratio of $13.6(\mathrm{P}=0.01)$ for the prevalence of emphysema for the two highest quartiles of the SHTS exposure score, even when adjusted to age, gender, Asian ethnicity, and history of asthma. The $3^{\text {rd }}$ and $4^{\text {th }}$ quartile of SHTS 
separately were significant $(\mathrm{P}=0.01$, and $\mathrm{P}=0.02)$, but were combined to have more stable estimates.

\section{Discussion}

Our study demonstrated an increase in the prevalence of lung cancer among those who also had CT evidence of emphysema, thereby demonstrating the importance of identifying emphysema when interpreting a CT scan of the chest. While this increased risk of lung cancer has been previously reported for smokers (3-6), this is the first such report for never smokers. In never smokers, when emphysema is identified as seen in $1.6 \%$ of never smokers in our report, that person has the same prevalence of lung cancer as a smoker. Further, it was shown, in a smaller subcohort of 3,266 never smokers on whom detailed SHTS exposure was documented, that the adjusted odds ratio of emphysema was significantly increased when there was moderate to high

SHTS exposure. Although it is unclear whether this increased risk of emphysema reflects some underlying chronic pulmonary condition or additional risk factors that predisposes to it, the finding of emphysema in a never smoker should be interpreted as a marker of increased lung cancer risk.

Smokers, both current and former, had a higher prevalence of lung cancer than never smokers in our study, as expected, as active smoking is the dominant risk factor for lung cancer (15). However, never smokers in our study had the same prevalence of lung cancer as light current and former smokers ( $<30$ pack-years) (Table 3). For smokers, the adverse effect of smoking on respiratory function has been extensively documented as cigarette smoke was considered to be the single most important risk factor for COPD (15-18). Table 3 clearly illustrates the increase in prevalence of lung cancer and emphysema by increased cumulative 
smoking. CT-detected emphysema by itself has been shown to be a strong, independent risk factor for lung cancer in the CT screening studies for lung cancer (3-6).

Further evidence of the association of SHTS and COPD comes from more than 50 additional studies summarized in the 2006 Surgeon General report (19). These studies included ones that carefully considered potential sources of bias and confounding of this association and identified the damage of SHTS on the respiratory health of children. Fewer studies have analyzed its effect on adults, partly due to the challenges in studying chronic diseases that may only become clinically apparent after 20 or more years of exposure. An association of SHTS and COPD was also reported in 4 of the 5 studies reported by Tredaniel et al. (20). Data from 3 national health and nutrition surveys, including the NHANES study, found that among 12,980 never smokers, aged 18-74 years, the prevalence of physician-diagnosed chronic obstructive pulmonary disease (COPD) was $3.7 \%$ for men and $5.1 \%$ for women $(21,22)$. These rates are higher than the prevalence of emphysema found in our study, but our study was limited to CTdetected emphysema and not on the other respiratory illnesses included in the definition of COPD. Jordan et al. (23) demonstrated a doubling of risk of COPD (OR 1.98, 95\% CI 1.033.79) for SHTS exposures over 20 hours per week. A large prospective study, the European Prospective Investigation into lung cancer and nutrition (EPIC) (24), concluded the SHTS is a risk factor for lung cancer and other respiratory diseases, including emphysema, in smokers and never smokers. Further, flight attendants heavily exposed to SHTS, compared to a matched sample from NHANES 2005-2009, had an increased prevalence of chronic bronchitis (11.7 vs. $7.2 \%, \mathrm{P}=0.05)$, emphysema/COPD (3.2\% vs. $0.9 \%, \mathrm{P}<0.03)$, despite a lower prevalence of other medical illnesses (25). The worldwide effect of SHTS has been summarized in more recent articles $(26,27)$. 
A limitation of our study is that the smoking status was self reported, and this may lead to misclassification of the actual smoking status of the participant, particularly among never smokers. However, our reported prevalence rates of lung cancer and emphysema are in line with many other publications cited above. Our never smoker cohort included individuals who had occupational and SHTS exposure, but our reported rate of emphysema is lower than that reported for COPD in prior studies $(20,22)$. This is understandable as we reported only the CT finding of emphysema and did not include airway obstruction which is included in the definition of COPD. The possibility of some misclassification of never smokers may be present, however the failure to correct for background exposure to SHTS in most epidemiologic studies (as truly unexposed populations are essentially unavailable) might bias the associations toward the null (28).

Important findings of our report is that the identification of emphysema in low-dose CT scans provides additional information as to the risk of lung cancer and that this increased risk of lung cancer suggests using same frequency of annual repeat CT screening for those with emphysema, regardless of whether the person smoked or was a never smoker. 


\section{Acknowledgements}

This report has been funded in part by the Flight Attendant Medical Research Institute. The sponsor had no involvement in any study design, data collection, data analysis and interpretation and manuscript writing.

The screenings in the I-ELCAP pooled database has been supported in part by National Institutes of Health R01-CA-633931 and R01-CA-78905; Department of Energy DE-FG02-96SF21260; The City of New York, Department of Health and Mental Hygiene; New York State Office of Science, Technology and Academic Research (NYSTAR); Institute de Salud Carlos III, Spain (PI10/01652, PI07/0792, RD12/0036/0062); American Cancer Society; The Starr

Foundation; The New York Community Trust; The Rogers Family Fund; The Foundation for Lung Cancer: Early Detection, Prevention, and Treatment (primary source from an unrestricted gift in 2000-2003 from the Vector Group, the parent company of Liggett Tobacco); Dorothy R. Cohen Foundation, Jacob and Malka Goldfarb Charitable Foundation; Auen/Berger Foundation; Berger Foundation; Mills Peninsula Hospital Foundation, Tenet Healthcare Foundation; Ernest E. Stempel Foundation; Academic Medical Development Corporation; Columbia University Medical Center, Empire Blue Cross and Blue Shield; Eastman-Kodak Corporation; General Electric Corporation; Weill Medical College of Cornell University; Cornell University; New York Presbyterian Hospital; Swedish Hospital; Christiana Care Helen F. Graham Cancer Center; Holy Cross Hospital; Eisenhower Hospital; Jackson Memorial Hospital Health System; Evanston Northwestern Healthcare.

\section{Potential Conflicts of Interest:}

- Dr. Yankelevitz is a named inventor on a number of patents and patent applications relating to the evaluation of diseases of the chest including measurement of nodules. Some of these, which are owned by Cornell Research Foundation (CRF), are nonexclusively licensed to General Electric. As an inventor of these patents, Dr. Yankelevitz is entitled to a share of any compensation which CRF may receive from its commercialization of these patents. Dr. Yankelevitz also serves on the scientific advisory board (unpaid) for Give-A-Scan, Lung Cancer Alliance.

- Dr. Henschke is also an inventor of the patents and pending patents owned by Cornell Research Foundation (CRF). As of April 2009, she has divested herself of all royalties and other interests arising from these.

- Others: None 


\section{References}

1. Berrington de González A, Mahesh M, Kim KP, Bhargavan M, Lewis R, Mettler F, Land C. Projected cancer risks from computed tomographic scans performed in the United States in 2007. Arch Intern Med. 2009; 169: 2071-2077

2. Henschke CI, Yip R, Yankelevitz DF, Smith JP for the I-ELCAP Investigators. Definition of a positive test result in computed tomography screening for lung cancer. Annals of Internal Medicine 2013; 158: 246-252

3. De Torres JP, Bastarrika G, Wisnivesky JP et al. Assessing the relationship between lung cancer risk and emphysema detected on low-dose CT of the chest. Chest 2007; 132: 19321938

4. Wilson DO, Weissfeld JL, Balkan A. et al. Association of radiographic emphysema and airflow obstruction with lung cancer. Am J Respir Crit Care Med 2008; 178: 738-44

5. De Torres JP, Bastarrika G, Zagaceta J. et al. Emphysema presence, severity, and distribution has little impact on the clinical presentation of a cohort of patients with mild to moderate COPD. Chest 2011; 139: 36-42

6. Zulueta JJ, Wisnivesky JP, Henschke CI, et al. Emphysema scores predict death from COPD and lung cancer. Chest 2012; 141: 1216-23.

7. Henschke CI, McCauley DI, Yankelevitz DF, et al. Early Lung Cancer Action Project: overall design and findings from baseline screening. Lancet. 1999; 354: 99-105

8. New York Early Lung Cancer Action Project Investigators. CT Screening for lung cancer: diagnoses resulting from the New York Early Lung Cancer Action Project. Radiology 2007; 243: $239-249$ 
9. International Early Lung Cancer Action Program Investigators. Survival of patients with stage I lung cancer detected on CT screening. N Engl J Med 2006; 355: 1763-71.

10. Pastorino U, Bellomi M, Landoni C, et al. Early lung-cancer detection with spiral CT and positron emission tomography in heavy smokers: 2-year results. Lancet 2003; 362: 593-7.

11. The National Lung Screening Trial Research Team. Reduced lung-cancer mortality with lowdose computed tomographic screening. N Engl J Med 2011;365:395-409

12. MacMahon H, Austin JH, Gamsu G, et al. Guidelines for management of small pulmonary nodules detected on CT scans: a statement from the Fleischner Society. Radiology 2005; 237: $395-400$

13. International Early Lung Cancer Action Program protocol. http://www.ielcap.org/sites/default/files/ielcap.pdfAccessed on August 12, 2013

14. Yankelevitz DF, Henschke CI, Yip R, et al. Secondhand tobacco smoke in never smokers is a significant risk factor for coronary artery calcification. JACC Imaging 2013; 6: 651 -657

15. U.S. Public Health Service. Smoking and Health: Report of the Advisory Committee to the Surgeon General of the Public Health Service. Washington, DC: U.S. Government Printing Office, 1964. 33.

16. Thun MJ, Heath CW Jr. Changes in mortality from smoking in two American Cancer Society prospective studies since 1959. Prev Med. 1997 Jul-Aug;26(4):422-6.

17. Cardenas VM, Thun MJ, Austin H, Lally CA, Clark WS, Greenberg RS, Heath CW Jr. Environmental tobacco smoke and lung cancer mortality in the American Cancer Society's Cancer Prevention Study. II. Cancer Causes Control. 1997; 8: 57-64.

18. Thun MJ, Lally CA, Flannery JT, Calle EE, Flanders WD, Heath CW Jr. Cigarette smoking and changes in the histopathology of lung cancer. J Natl Cancer Inst. 1997; 89: 1580-6. 
19. Office on Smoking and Health (US). The Health Consequences of Involuntary Exposure to Tobacco Smoke: A Report of the Surgeon General. Atlanta (GA): Centers for Disease Control and Prevention (US); 2006.

20. Tredaniel J. Boffetta P, Saracci R, Hirsch A. Exposure to environmental tobacco smoke and adult non-neoplastic respiratory diseases. Eur Respir J 1994; 7: 173-185

21. Whittemore AS, Perlin SA, DiCiccio Y. Chronic obstructive pulmonary disease in lifelong non-smokers: results from NHANES. Am J of Public Health 1995; 85: 702-706

22. Coultas DB, Mapel D, Gagnon R, Lydick E. The health impact of undiagnosed airflow obsetruction in a national sample of United States adults. Am J Respir and Crit Care Med 2001; 164: 372-377

23. Jordan RE, Cheng KK, Miller MR, Adab P. Passive smoking and chronic obstructive pulmonary disease: cross-sectional analysis of data from the Health Survey for England. BMJ Open 2011;1: e000153.

24. Vineis P, Airoldi L, Veglia F, Olgiati L, Pastorelli R, Autrup H, et al. Environmental tobacco smoke and risk of respiratory cancer and chronic obstructive pulmonary disease in former smokers and never smokers in the EPIC prospective study. BMJ 2005; 330: 277.

25. Beatty AL, Haight TJ, Redberg RF. Associations between respiratory illnesses and secondhand smoke exposure in flight attendants: A cross-sectional analysis of the Flight Attendant Medical Research Institute Survey. Environ Health 2011; 10: 81.

26. Oberg M, Jaakkola MS, Woodward A, Peruga A, Prüss-Ustün A. Worldwide burden of disease from exposure to second-hand smoke: a retrospective analysis of data from 192 countries. Lancet 2011; 377: 139-46. 
27. US Department of Health and Human Services. How tobacco smoke causes diseases: the biology and behavioral basis for smoking-atttributable disease: a report of the Surgeon General. Rockville (MD): US. Department of Health and Human Services, Public Health Service, Office of Surgeon General, 2010 (cited 2011 Nov 30) available from: http://www.surgeongeneral.gov/library/tobaccosmoke/report/full_report.pdf

28. Ong EK and Glantz SA. Tobacco industry efforts subverting International Agency for Research on Cancer's second-hand smoke study. Lancet 2000; 355: 1253-1259 
Table 1. Gender, ethnicity, age and smoking history for current, former, and never smokers.

Table 2. Prevalence of diagnosed lung cancer cases and emphysema by age in 23,415 current smokers, 26,341 former smokers and 12,368 never smokers, all asymptomatic for lung cancer

Table 3. Prevalence of lung cancer and emphysema in current and former smokers by pack-years of smoking

Table 4. Logistic regression analysis of prevalence of lung cancer in relation to the presence of emphysema, conditionally on age, female gender, and Asian ethnicity. Analysis performed separately for current smokers, former smokers, and never smokers.

Table 5. Logistic regression analysis of the prevalence of emphysema in 3,266 asymptomatic never smokers for SHTS adult exposure, conditionally on age, male, Asian ethnicity, and self report of history of asthma. 
Table 1. Gender, ethnicity, age and smoking history for current, former, and never smokers.

\begin{tabular}{|c|c|c|c|c|}
\hline & Current smokers & Former smokers & Never smokers & $\mathrm{P}$-value \\
\hline & $N=23415$ & $\mathrm{~N}=26341$ & $N=12368$ & \\
\hline \multicolumn{5}{|l|}{ Gender } \\
\hline Male & $13377 \quad(57 \%)$ & $16263(62 \%)$ & $6514 \quad(53 \%)$ & $<.0001$ \\
\hline Female & $10038(43 \%)$ & $10078 \quad(38 \%)$ & $5854 \quad(47 \%)$ & \\
\hline \multicolumn{5}{|l|}{ Ethnicity } \\
\hline White & $18298 \quad(78 \%)$ & $23532(89 \%)$ & $5940 \quad(48 \%)$ & $<.0001$ \\
\hline Asian & $2385 \quad(11 \%)$ & $1368(5 \%)$ & $5800 \quad(47 \%)$ & \\
\hline Other & $2732(12 \%)$ & $1441 \quad(5 \%)$ & $628 \quad(5 \%)$ & \\
\hline \multicolumn{5}{|l|}{ Age } \\
\hline Median(IQR) & $57(52-63)$ & $62(57-68)$ & $56(50-65)$ & $<.0001$ \\
\hline \multicolumn{5}{|l|}{ Smokers } \\
\hline $\begin{array}{l}\text { Median pack- } \\
\text { years (IQR) }\end{array}$ & $35(23-49)$ & $30(19-47)$ & & $<.0001$ \\
\hline $\begin{array}{l}\text { Median years quit } \\
\text { (IQR) }\end{array}$ & - & $15(6-24)$ & & \\
\hline
\end{tabular}


Table 2. Prevalence of diagnosed lung cancer cases and emphysema by age in 23,415 current smokers, 26,341 former smokers and 12,368 never smokers, all asymptomatic for lung cancer

\author{
Current Smokers \\ \# participants \\ \# with lung cancer \\ Prevalence of lung cancer \\ \#. with emphysema
}

Prevalence of emphysema

\section{Former smokers}

\# participants

\# with lung cancer

Prevalence of lung cancer

\#. with emphysema

Prevalence of emphysema

\begin{tabular}{cccccc}
\multicolumn{7}{c}{ Age (years) } \\
$\mathbf{4 0 - 5 0}$ & $\mathbf{5 0 - 6 0}$ & $\mathbf{6 0 - 7 0}$ & $\mathbf{7 0 - 8 0}$ & $\mathbf{8 0 - 9 0}$ & Total \\
2,937 & 10,783 & 7,823 & 1,744 & 128 & 23,415
\end{tabular}

$\begin{array}{ccccccc}9 & 96 & 167 & 56 & 5 & 333 & \\ 0.3 \% & 0.9 \% & 2.1 \% & 3.2 \% & 3.9 \% & 1.4 \% & \mathrm{P}<0.0001\end{array}$

$\begin{array}{llllll}421 & 2,629 & 2,812 & 768 & 54 & 6,684\end{array}$

$\begin{array}{lllllll}14.3 \% & 24.4 \% & 35.9 \% & 44.0 \% & 42.2 \% & 28.5 \% & \mathrm{P}<0.0001\end{array}$

\section{Never smokers}

\# participants

\# with lung cancer

Prevalence of lung cancer

\#. with emphysema

Prevalence of emphysema

\section{$1,313 \quad 8,137 \quad 11,238 \quad 4,990 \quad 663 \quad 26,341$}

$\begin{array}{ccccccc}1 & 48 & 132 & 92 & 10 & 283 & \\ 0.1 \% & 0.6 \% & 1.2 \% & 1.8 \% & 1.5 \% & 1.1 \% & \mathrm{P}<0.0001\end{array}$

$\begin{array}{llllll}107 & 1,092 & 2,557 & 1,453 & 213 & 5,422\end{array}$

$\begin{array}{lllllll}8.1 \% & 13.4 \% & 22.8 \% & 29.1 \% & 32.1 \% & 20.6 \% & \mathrm{P}<0.0001\end{array}$


Table 3. Prevalence of lung cancer and emphysema in current and former smokers by pack-years of smoking

\begin{tabular}{|c|c|c|}
\hline Smoking & Overall & Pack-years of smoking \\
\hline status & prevalence & $30-59$ \\
\hline
\end{tabular}

\section{Prevalence of lung} cancer

$\begin{array}{lllll}\text { Current } & 1.4 \% & 0.6 \% & 1.6 \% & 2.8 \% \\ \text { Former } & 1.1 \% & 0.4 \% & 1.3 \% & 2.4 \%\end{array}$

\section{Prevalence of} emphysema

$\begin{array}{lllll}\text { Current } & 28.5 \% & 17.5 \% & 32.7 \% & 41.9 \% \\ \text { Former } & 20.6 \% & 10.9 \% & 25.3 \% & 37.5 \%\end{array}$


Table 4. Logistic regression analysis of prevalence of lung cancer in relation to the presence of emphysema, conditionally on age, female gender, and Asian ethnicity. Analysis performed separately for current smokers, former smokers, and never smokers.

\begin{tabular}{|c|c|c|c|}
\hline Current Smokers & OR & $95 \% \mathrm{CI}$ & P-value \\
\hline Emphysema & 1.8 & $(1.4,2.2)$ & $<.0001$ \\
\hline Age in decades & 2.0 & $(1.7,2.3)$ & $<.0001$ \\
\hline Female & 1.1 & $(0.9,1.4)$ & 0.36 \\
\hline Asian ethnicity & 0.8 & $(0.5,1.3)$ & 0.40 \\
\hline
\end{tabular}

Former Smokers

Emphysema

Age in decades

Female

Asian ethnicity

Never smokers

Emphysema

Age in decades

Female

Asian ethnicity

$\begin{array}{lcc}\text { OR } & \text { 95\% CI } & \text { P-value } \\ \mathbf{1 . 7} & (\mathbf{1 . 3}, \mathbf{2 . 2}) & <.0001 \\ 1.8 & (1.5,2.0) & <.0001 \\ 2.0 & (1.6,2.5) & <.0001 \\ 0.7 & (0.3,1.5) & 0.35\end{array}$

OR $95 \%$ CI P-value

$6.3 \quad(2.4,16.9) \quad 0.0003$

$1.5 \quad(1.2,2.0) \quad 0.0018$

$1.1 \quad(0.6,2.0) \quad 0.64$

$2.1 \quad(1.1,3.9) \quad 0.017$ 
Table 5. Logistic regression analysis of the prevalence of emphysema in 3,266 asymptomatic never smokers for SHTS adult exposure, conditionally on age, male, Asian ethnicity, and self report of history of asthma.

Never smokers $\quad$ OR $\quad 95 \%$ CI $\quad$ P-value

SHTS Quartiles

$\begin{array}{rccc}\text { 1st quartile } & \text { Ref } & & \\ \text { 2nd quartile } & 4.8 & (0.5,47.2) & 0.18 \\ \text { 3rd/4th quartile } & 13.6 & (1.7,106.1) & 0.01\end{array}$

$\begin{array}{lccc}\text { Age (in decade) } & 2.0 & (1.3,3.0) & 0.001 \\ \text { Male } & 1.2 & (0.5,2.9) & 0.71 \\ \text { Asian } & 3.8 & (1.5,9.5) & 0.01 \\ \text { Asthma } & 1.1 & (0.2,4.9) & 0.90\end{array}$

